\title{
Microcredit Schemes: A Tool for Promoting Rural Savings Capacity among Poor Farm Families: A Case Study in the Eastern Region of Ghana
}

\author{
Mercy Asamoah*, Franklin Manu Amoah \\ Cocoa Research Institute of Ghana (CRIG), New-Tafo Akim, Ghana \\ Email: ${ }^{*}$ mrcyasamoah@yahoo.com
}

Received 15 November 2014; revised 17 December 2014; accepted 25 December 2014

Copyright (C) 2015 by authors and Scientific Research Publishing Inc.

This work is licensed under the Creative Commons Attribution International License (CC BY). http://creativecommons.org/licenses/by/4.0/

(c) (i) Open Access

\section{Abstract}

Savings mobilization is crucial for any viable economic and investment activity. In rural agriculture, the ability to save or to mobilize capital in cash at bank or stock of wealth is a major prerequisite as the collateral for accessing bank loans. The ability to save among rural poor households is however, difficult due to their low income levels and inability to make personal savings commitment. According to Yunus (2000) [1], failure of traditional financial institutions to extend credit to the poor is the single most important reason for the perpetuation of poverty. Nevertheless, since the early 1980s, microfinance scheme has been identified as a useful tool that can effectively mobilise savings among poor households. Yunus (2003) [2] indicated that micro-credit schemes have developed unique characteristics in terms of unconventional approaches, organizational and lending procedures that have resulted in high rates of repayments, savings mobilization and the ability to nurture a culture of commitment and self-reliance of poor people. The objective of this study was to assess the role microfinance plays in savings mobilization among farm households, analyse the extent of savings mobilized by participants and evaluate the conditions for membership of such schemes. A total of 212 respondents in organised cocoa farmer Associations since 2010 in the Eastern region were interviewed using formal questionnaires. The results indicated that the microfinance model had helped the respondents, mainly small-scale cocoa farmers, to mobilize substantial savings in a convenient and tailor made way. The majority who did not have any savings culture before joining the schemes were surprised about their savings potential through the group concept. Also, the schemes allayed the fear of the participants to take credit from financial institutions with high (over 95\%) repayment culture using peer support, group guarantee and social capital generated through the formation of associations. They also had easy

\footnotetext{
${ }^{*}$ Corresponding author.
} 
access to farm inputs such as fertilizer to maintain their cocoa farms because of their savings mobilization. It is concluded that microfinance model is a potential tool that promotes savings culture which gives access to credit for small-scale cocoa farmers to purchase farm inputs to increase productivity and enhance their livelihood.

\section{Keywords}

\section{Savings, Cocoa, Farmers, Microcredit}

\section{Introduction}

Most rural farm families lack access to effective and sustainable finance to support their businesses. The majority also have limited knowledge and skills to generate additional income from alternative sources to support farm income. These lead to low productivity and poor standard of living (Asamoah, 2013) [3]. Since farmers lack adequate savings on their own, they have to seek capital from either the formal or informal sector which usually goes with high interest rates. Irrespective of the source of capital, three main pre-requisites are usually demanded including personal savings and/or high repayment culture, landed property (including cocoa farms) and also availability of qualified guarantors, usually, formal sector employees whose salaries pass through the banks. These requirements seriously challenge the rural farmer's access to financial assistance from the banks. In Ghana, IFAD (2000) [4] gave an estimate of access to financial services to be around 8\% in 1998. Farmers save small amounts of money or livestock in order to finance life-cycle demands including food, children's education, and for emergencies.

Before the liberalization of the internal marketing of cocoa in the early 1990s, the then Produce Buying Company (PBC), which was a subsidiary of the Ghana Cocoa Board and the sole purchaser of dry cocoa beans in Ghana, used to support cocoa farmers with financial assistance for farm maintenance. Unfortunately, the liberalization brought along some unintended consequences such as the keen competition it engendered among the many licensed cocoa buying companies. Some of these consequences were dishonesty, abuses in repayment of loans and diverting pledged dry cocoa beans to other buying agencies to avoid payments of loans. Also, the payment of cocoa by cash instead of the previous "Akuafo Cheque” that aligned farmers to banks almost ceased since most farmers preferred cash at their door step to the issuance of cheques. These negative consequences worsened farmers' access to loans especially, from commercial banks and financial institutions.

The limitation in mobilizing farm credits due to low productivity and low income of small-scale cocoa farmers prompted the need for a suitable, tailor-made and sustainable credit scheme for cocoa farmers especially, women. Thus, a number of microfinance schemes, in the Eastern region were evaluated in 2006 (Asamoah, 2007) [5]. It was realized then that microfinance, with its particular characteristics, could be used as a potential tool to build the capacity of the farmers in order to enable them mobilize savings gradually and conveniently qualify for loans using social collateral and group support as guarantee. The findings from that study informed a pilot microcredit programme among some selected small-scale cocoa farmers in the Eastern region of Ghana. The savings capacity of these farmer associations have been monitored for over three years and this study also highlights their savings capacity.

Microfinance is the provision of small financial services such as credit, savings, insurance and other basic services to poor and low-income people. In Ghana, microfinance evolved through the traditional informal "Susu" collection system which relied heavily on group solidarity and has passed through various transformations to its present models. Due to its potentials, many organizations are now providing microfinance services in the form of savings and loans including governmental, non-governmental organizations (NGOs), Credit Unions, Cooperatives, banks and other financial institutions. According to Asamoah (2007) [5], under the right conditions, access to a sustainable microcredit, enables poor people to increase their incomes, build assets and also enhance the growth of their small scale businesses. In rural communities, particularly, among women and small-scale cocoa farmers, the culture to save at bank is a daunting task. Yet, this is a major prerequisite for accessing commercial loans to purchase farm inputs.

However, with the absence of farmer-friendly structures in formal financial sectors, and preference for cash 
payment instead of the Akuafo cheque system that compulsorily linked them to formal banks farmers are almost cut off from accessing formal sector loans. This is due mainly to lack of collateral security and/or the acceptable savings account required. The objectives of this paper are thus, to assess the role that Microcredit schemes play in rural savings mobilization, analyse the extent of savings mobilization among some beneficiary small-scale cocoa farmers and critique the conditions for membership of such schemes.

\section{Research Method}

A combination of formal and action-based participatory methods was employed in the pilot microcredit study from 2010 to 2013. Responses were collected from more than 300 participants (cocoa farmers) of the schemes. These cocoa farmers were animated in self-help associations since 2010 by the Social Science and Statistics Unit of the Cocoa Research Institute of Ghana (CRIG) in an action-based research with the aim of developing a model credit scheme suitable for cocoa farmers. Out of this 300 participants, baseline data were collected from 212 of them using formal questionnaires. The questionnaires were analysed descriptively using Statistical Package for Social Science (SPSS version 16). Beside the baseline information, data from the three year monitoring report of the farmers' savings mobilization were also used. This paper thus, shares the findings from the baseline and the monitoring report.

\section{Results and Discussions}

\subsection{Background Characteristics of Respondents}

This section gives a brief background of the respondents' age, educational levels, main occupation and length of participation in the schemes. Twenty five percent of the respondents were above sixty years old (Table 1). Since the respondents were mainly cocoa farmers, the age structure was found to be normal with cocoa farmer population in Ghana.

\subsection{Educational Levels of Respondents}

Educational levels were generally low among the respondents with the majority having up to basic school education (Table 2). Since educational level correlates well with job opportunities and income, especially, in the formal sector it stands to reason that the majority of those in the microcredit schemes are in the informal sector (Table 2) and need small amounts of capital to either start or enhance their working capital. The educational level also shows why most of the respondents felt uncomfortable with formal banking systems (for savings

Table 1. Age distribution of respondents.

\begin{tabular}{cc}
\hline Age (Years) & \% of Respondents \\
\hline Up to 40 & 21.2 \\
$41-50$ & 25.5 \\
$51-60$ & 28.3 \\
Above 60 & 25.0 \\
\hline
\end{tabular}

Source: field data.

Table 2. Highest educational levels of respondents.

\begin{tabular}{cc}
\hline Level & \% of Respondents (2010) \\
\hline No/Non Formal & 16.5 \\
Primary/Junior High School & 75.0 \\
Senior High/tertiary & 8.5 \\
\hline
\end{tabular}

Source: field data. 
deposits or withdrawal) where one needs to fill and endorse bank forms which are cumbersome to some extent or seek assistance from officials who sometimes are unfriendly.

\subsection{Main Occupation of Respondents}

Farming was the major source of employment and income for all the respondents although some especially, the women, also engaged in economic activities such as petty trading, palm oil extraction and sale of cooked food for additional sources of income. With these livelihood strategies which were operated on small-scale, available income was low and the respondents needed motivation and sensitization to be able to save.

\subsection{Length of Membership in the Microcredit Schemes}

The respondents had participated in the schemes for up to three years and more. Since the schemes were voluntary, new members were admitted at any time while non-compliant members were sacked. Non compliance mainly stemmed from refusal or delay in the payment of one's savings contribution and also for non attendance at group meetings.

\subsection{The Role of Microcredit Schemes in Rural Savings Mobilization}

Microcredit schemes play key role in rural savings mobilization by progressively facilitating group formation at the local communities, inspiring cooperative, team spirit and self-confidence as well as establishing social capital. These progressive roles are the pillars of the savings capacity among small-scale farmers, especially, poor women. Sensitization is conducted to make the people appreciate the essence of saving and to develop a sense of belonging and self-worth among people of similar socio-economic characteristics. After this, participants get the will power to start actual savings mobilization however small the amount may be. Microcredit schemes make participants believe in their own ability to cause significant changes in their lives through micro-savings. With the build up of social capital, members trust that lending of support (example, helping members to break cocoa pods in order to get them ready for sale) to another member will yield a reciprocal support when the giver is in a similar need in future. It is this concept of reciprocity that also help to sustain members' interest in the schemes.

\subsection{Development of Savings Culture and Mobilization}

Apart from the attributes discussed above, microcredit schemes actually nurture members saving culture from small to big savings with time. All the schemes studied linked credit supply with compulsory group savings and personal savings. Savings has thus, become an organic component to most microcredit schemes, also to ensure the sustainability of such schemes.

Apart from compulsory savings the mode of collection of the savings is convenient for the farmers. Some make weekly, bi-weekly or monthly contributions during meeting times. This helps them to avoid traveling far to deposit monies at banks. Participants were encouraged to save continuously for ten months or more after which they could access credit including farm inputs like fertilizer. Depending on repayment culture, old members could access loans upon approval by the executives. This condition was a proxy indicator to assess their commitment to loan servicing. It is believed that if one is unable to effectively contribute to own personal savings with a high sense of commitment, then it is unlikely that when given loans, repayment would be effective.

It is important to note that findings from the study has confirmed that rural savings are a vast untapped resources, and that the rural poor have much larger savings capacities than usually assumed if given the enabling environment including regular small and convenient savings. For instance, less than $50 \%$ of respondents were making the effort to save before they joined the schemes. However, all of them were making regular weekly or monthly savings which were encouraging and being monitored.

Indeed, apart from collateral security, one of the factors inhibiting the poor from accessing bank credit is the inability to save at the banks. Thus, participation in the schemes allowed the participants to develop and/or to enhance their savings culture which also helped them to get personal loans with group guarantee. Sinapi Aba Trust (SAT), for instance, provided another innovative option for savings (Asamoah, 2007) [5]. Respondents in SAT scheme were supposed to save $10 \%$ of each loan received as compulsory savings into group account. In that case, a client did not need to wait for a three month period or more before being eligible for subsequent loans. Also, alongside the repayment of loans, all the groups, encouraged their clients to continue to enhance 
their savings mobilization. Thus, by the time loans are repaid, participants would have mobilised some more savings which could also cushion them in times of need.

\subsection{Savings Mobilisation among Small Scale Cocoa Farmer Groups between 2011 and 2013}

The group savings culture was very encouraging. They made prompt payment of savings for a period of ten months from January to October within a year into a savings and loans club. After twelve months, the accumulated savings together with accrued interest is shared among members and members have the option to withdraw full or part of savings or roll over the entire amount into the following year. Table 3 depicts the principal savings capacity of the small scale cocoa farmers who have formed associations in their various communities. Membership of each group was between thirty to fifty-six.

Since cocoa farming is usually seasonal, some members make bulk payments during the major season from income derived from the sale of dry cocoa beans. This is also, a welcome investment culture among poor farm families whose incomes may be seasonal. Also, individual farmers who have diversified income sources save more in their own individual names. For instance, a few of such in the Akooko group were able to save between GH\$1000.00 and GH\$5000.00 per annum which is very laudable considering the fact that they could not do so before they joined the microfinance schemes.

Apart from Nkronso farmers association that reduced their savings in 2013, all other groups including new entrants increased their total savings. The reduction in savings of Nkronso farmers association was mainly due to a misunderstanding between the leadership of the group and a couple of the members. The savings of the aggrieved members were ceased until all other members who owed the cost of fertilizer had defrayed their debts fully. This brought misunderstanding and subsequently stoppage of their individual saving contribution. This is normal among farmer groups since the group's total savings is always used to guarantee loans (input credit) for members.

\subsection{Savings Capacity and Access to Inputs}

The majority of Ghanaian cocoa farmers operate on small to medium scale with low productivity of between 250 to $650 \mathrm{~kg}$ per hectare (CRIG, 2010) [6]. However, one of the major constraints facing them is the lack of access to credit to purchase needed inputs. This lack is also a function of farmer's poor savings capacity. For instance, about $99 \%$ of cocoa farmers are being paid cash and actually prefer cash to the previous Akuafo cheque system of payment that linked them automatically to bank transactions. Thus, microcredit schemes and group formation build farmer's capacity both in savings and ability to purchase farm inputs.

In this current study, participants were able to purchase over 2600 bags of fertilizer within three years. Before this savings capacity, none of the respondents had ever used fertilizer which is a critical input to enhance cocoa production on their cocoa farms. Apart from the fertilizer, over one hundred small-scale cocoa farmers had also

\begin{tabular}{|c|c|c|c|}
\hline Name of Farmer Group & Total Savings 2013 & Total Savings 2012 & Total Savings 2011 \\
\hline Akooko & 18,550 & 10,950 & 8250 \\
\hline Nkronso & 1100 & 5900 & 6200 \\
\hline Agyapomaa & 3520 & 1830 & 450 \\
\hline Nyafoman & 5000 & 1274 & 1000 \\
\hline Anyinam & 1080 & - & - \\
\hline Gye Nyame, & 3400 & - & - \\
\hline Nyame Bekyere & 1650 & - & - \\
\hline Total & 34,300 & 19,954 & 15,900 \\
\hline
\end{tabular}

Note: the empty space (-) indicates that the group had not started savings yet. 
accessed cash loans for farm maintenance consecutively for three years. Once they repay old credit they become eligible for subsequent credit. Members did not need any special collateral security. Loans are given based on trust, grass-root leadership and social support for repayment. Peer review, group pressure and promise of continuity of the credit scheme upon successful repayment of previous credit reduced any financial risk of bad debt especially, among farmers who are classified as high risk by commercial banks. Apart from fertilizer, some of the cocoa farmers saved to purchase motorized spraying machines for insect control. Group savings is, thus, a window of opportunity for organized farmers to acquire farm inputs.

\subsection{Access to Loans, Repayment Culture and Business Turnover}

With enhanced savings capacity, participants of the microcredit schemes were able to take loans and repay successfully. Over $50 \%$ of the participants had taken credit in the form of fertilizers and/or cash for farm maintenance and children's education for up to six times or more within three years. This is noteworthy considering the fact that $84 \%$ of the respondents indicated fear in taking loans initially. Participation in the schemes had thus, given them an alternative to seeking financial assistance from money lenders who charged high interest rates. This repayment success is also a proxy indicator of respondent's savings capacity because the size of one's loan depends on the current savings build-up and previous repayment history. The microcredit schemes also helped some respondents especially, the women, to double their business (petty trading) turnover.

\subsection{Critique of the Conditions for Participating in the Microcredit Schemes}

Conditions for participating in the microcredit schemes and for accessing credit are inextricably linked together. They relate mainly to entry and exit rules, leadership, criteria for savings contribution and access to loans.

Membership policy of the farmer groups: Membership is voluntary but open to only residents of a community who are well known in terms of attitude and personal disposition. This is because members are obliged to attend bi/weekly meetings regularly and promptly which in itself is another condition. Failure to attend such group meetings for a number of times without any tangible reason incurs sanctions including expulsion from the group. Since entry is voluntary, exit on account of personal reasons aside of expulsion is also voluntary, but the group's conditions apply.

Age limit: There is no age limit but people who are within the productive years (18 to 65 years) are encouraged. Members, especially, leadership of the groups have the mandate to assess the character of a person who has expressed interest before being permitted to register.

Attendance at meetings: The member must also be willing to attend the regular meetings scheduled and stated by the groups in their social constitutions. Non-cooperating members could be disciplined by the leadership of the groups.

Registration fees/Group dues: Apart from regular attendance at meetings, payment of savings contribution is also compulsory pegged at a mutually agreed amount by the participating members of the microcredit. Registration fee applies and prospective members should be willing to pay the existing group dues in addition to individual savings contribution.

Leadership: The groups are also required to democratically elect five to seven members as leaders and draw their own social constitution to guide their operations. This includes all the rules of engagement and exit. Leadership should change in tandem with their social constitutions that are binding on all members. The leadership is supposed to be strong, principled and transparent. They are accountable to the group and have the right to discipline members in accordance with the group's social constitution. Vibrant leaders empower their members to help themselves socio-economically and financially.

\subsection{Conclusions and Recommendations}

Microcredit schemes nurtured and enhanced the savings capacity of the participants in the eastern region. It granted access to input without collateral security. Social capital created among participants made them jointly and severally responsible for each other's loan and social behaviours. Microcredit also made the farmers appreciate the value of co-operation at all levels as a means of helping themselves and sharing useful information on good farm management practices.

Nevertheless, proper social mobilization (formation of groups) is a prerequisite for effective use of micro- 
credit schemes as an instrument for empowering small scale farmers not only to save but to adopt best farm management practices. Through consultation with target clientele, appropriate microfinance products could be developed to offer multiple options of financial services to small scale cocoa farmers. Also, effective institutional support in the form of capacity building is needed to ensure transformational leadership, corporate culture of financial self-discipline and trust among group members.

\section{Acknowledgements}

The authors wish to express their gratitude to the Management of Cocoa Research Institute of Ghana (CRIG) for the great support for the research work and the permission to present this paper at the 24th Biennial Conference of the Ghana Science Association (GSA). They also wish to express their gratitude to Akosua K. Darkwah, Department of Sociology, University of Ghana, Legon for all her contributions. This publication number CRIG/02/ 2014/044/004 is published by kind courtesy of the Executive Director of CRIG.

\section{References}

[1] Yunus (2000) How Donor Funds Could Better Reach and Support Grassroots Microcredit Programmes. Working towards the Microcredit Summit's Goal and Core Themes. The Bangladesh Development Studies, 26, 1-13.

[2] Yunus, M. (2003) Banker to the Poor: Micro-Lending and the Battle Against World Poverty. Public Affairs, New York.

[3] Asamoah, M., Ansah, F.O., Anchirinah, V., Aneani, F. and Agyapong, D. (2013) Insight into the Standard of Living of Ghanaian Cocoa Farmers. Greener Journal of Agricultural Sciences, 3, 363-370.

[4] IFAD Ghana (2000) Pre-Appraisal Mission. Working Paper: "Re-Packing the Rural Finance Sub-Sector in Ghana Poverty, Gender and Rural Informal Sector Perspectives”. http://ifad.org/gender/learning/sector/finance/42.htp

[5] Asamoah Mercy (2007) Microcredit Schemes and Women’s Empowerment. Doctor of Philosophy Thesis, University of Ghana, Legon.

[6] Cocoa Research Institute of Ghana (CRIG) (2010) A Source Book for Sustainable Cocoa Production. 
Scientific Research Publishing (SCIRP) is one of the largest Open Access journal publishers. It is currently publishing more than 200 open access, online, peer-reviewed journals covering a wide range of academic disciplines. SCIRP serves the worldwide academic communities and contributes to the progress and application of science with its publication.

Other selected journals from SCIRP are listed as below. Submit your manuscript to us via either submit@scirp.org or Online Submission Portal.
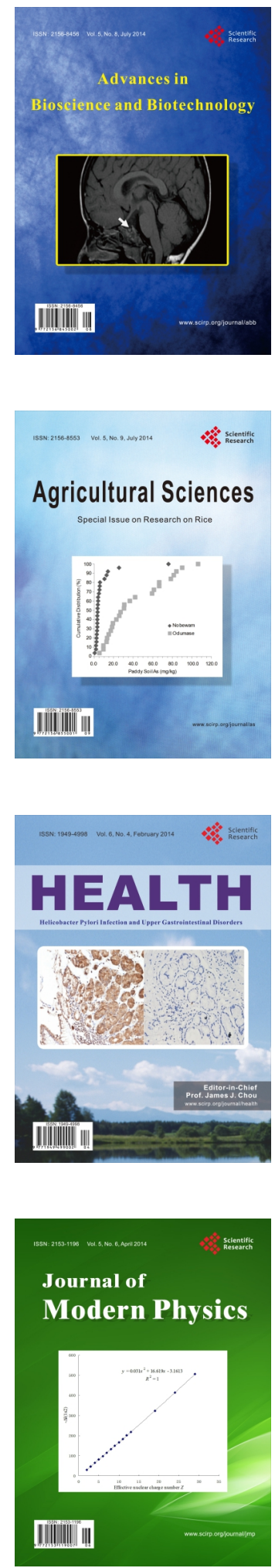
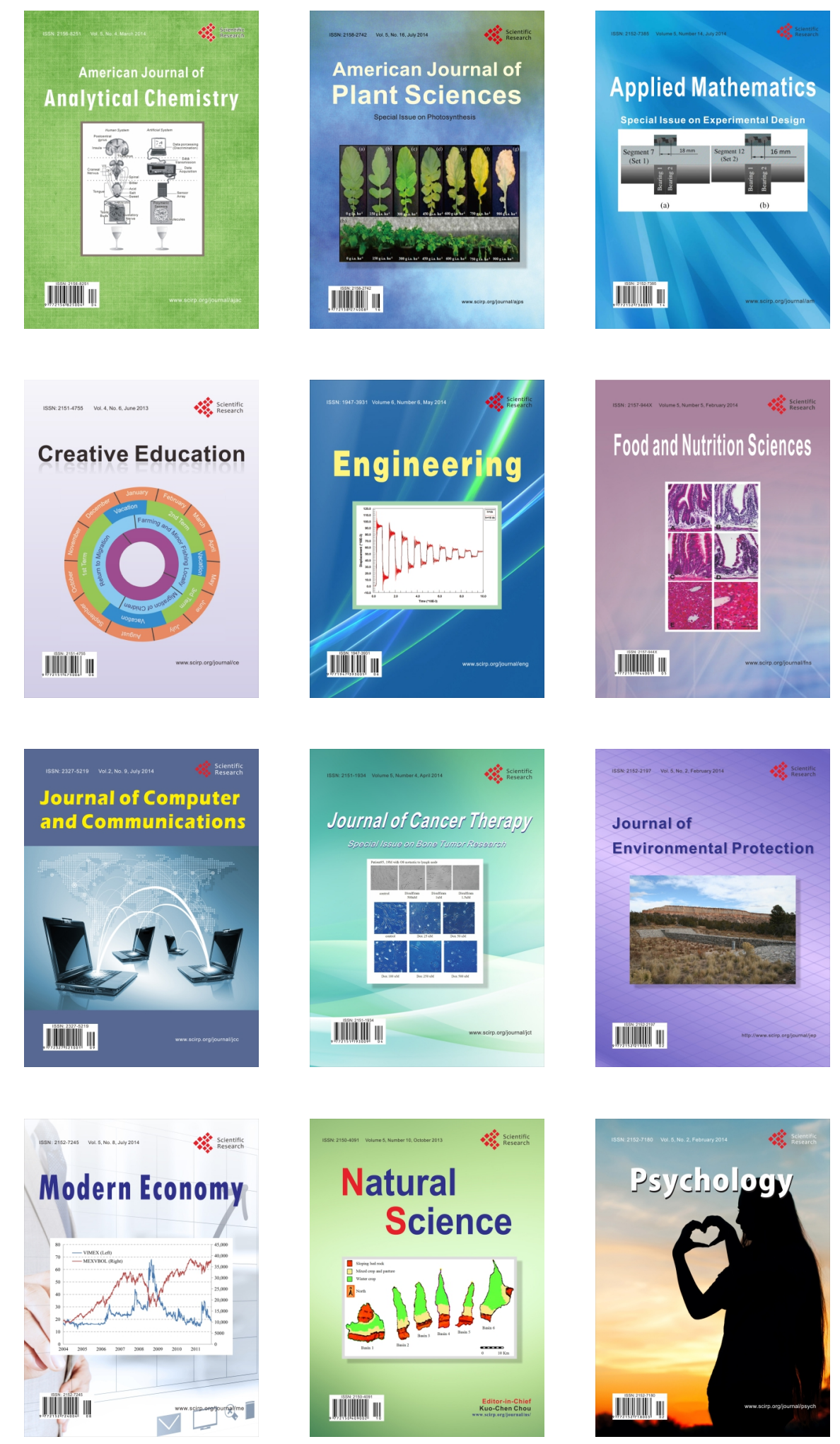